\title{
The psychometric properties of the Emotional Quotient Inventory 2.0 in South Africa
}

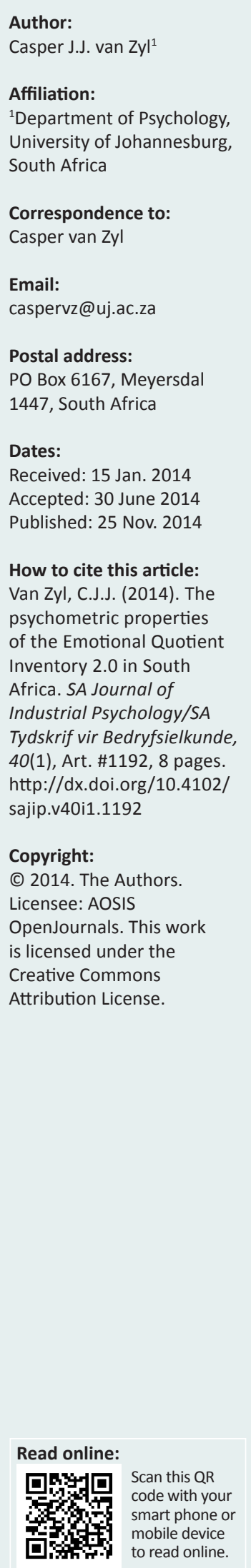

Orientation: Psychological assessments require continued refinement, updating and evaluation.

Research purpose: The purpose of this study is to examine the psychometric properties of the Emotional Quotient Inventory (EQ-i) 2.0 in South Africa. Item response and classical test theory methods are employed to investigate its item functioning and factor structure.

Motivation for the study: Although there has been some scientific research published on the EQ-i in South Africa, there has been no research on the revised version, the EQ-i 2.0. In addition, criticism has been levied against the estimation of internal consistency reliability in the field of emotional intelligence. This study aims to fill these gaps in the literature.

Research design, approach and method: This study followed a quantitative, non-experimental, cross-sectional design using secondary data. The sample comprised 1144 working adults (570 men and 574 women). The data were collected through an online platform as part of the standardisation process in South Africa.

Main findings: Results from Rasch analysis showed that almost all the items fit the model. Cronbach's alpha and McDonald's omega estimates revealed satisfactory reliabilities. Confirmatory factor analysis at the composite level revealed acceptable fit with the exception of the total EQ model.

Practical/managerial implications: This study supports the claim of reliability and validity of the EQ-i 2.0 in the South African context.

Contribution/value-add: The study contributes significantly to the international body of evidence regarding the psychometric properties of the EQ-i 2.0 and provides supporting evidence for the appropriate use of this assessment in South Africa.

\section{Introduction}

Much has occurred in the field of emotional intelligence (EI) since Salovey and Mayer's (1990) initial conceptualisation of the construct. Since then, many different models and measures of EI have emerged (Bar-On, 1997; Cameron, 1999; Cooper \& Sawaf, 1997; Goleman, 1995; Jordan, Ashkanasy, Hartel \& Hooper, 2002; Mayer, Salovey, Caruso, \& Sitarenios, 2003; Schutte et al., 1998; Wong \& Law, 2002). There has also been considerable interest in this topic, both in the popular press (Goleman, 1995) and amongst scientists as a result of studies reporting encouraging construct and predictive validities for the construct (e.g. Joseph \& Newman, 2010; O’Boyle, Humphrey, Pollack, Hawver \& Story, 2010; Van Rooy \& Viswesvaran, 2004).

However, EI is not a homogenous construct. When interpreting research from the EI literature, it is important to distinguish between the models and measures being studied because there are substantial differences between them. Petrides and Furnham (2001) have suggested differentiating between ability EI and trait EI; the former includes specific abilities measured on maximum performance tests and the latter includes self-perceived behavioural dispositions indicated on self-report tests. Other researchers divide EI research into three streams: the ability-based model of Salovey and Mayer (1990), self-report measures based on this model and mixed models of EI (Daus \& Ashkanasy, 2005). The mixed models could arguably be categorised further given the conceptual differences amongst them. Indeed, given the variety of EI models and measures, it is important to avoid the jingle fallacy, in which the assumption is made that two different constructs are the same because they bear the same name, and the jangle fallacy, in which similar constructs are believed to be different because they are named differently (Gignac, 2009). In fact, much of the criticism against the concept of EI is due to discriminant and convergent confusion between EI models and other established constructs like intelligence and personality (Conte, 2005; Locke, 2005; Matthews, Zeidner \& Roberts, 2002). 
The focus of the present study is on Bar-On's (1997) model of EI, which was operationalised in the Emotional Quotient Inventory (EQ-i) and the revised model (EQ-i 2.0; Multi Health Systems, 2011). The particular aim of the study is to investigate the psychometric properties of the EQ-i 2.0 in South Africa. This will be done by investigating item functioning following an item response theory (IRT) approach, examining internal consistency by computing Cronbach's alpha and McDonald's omega reliability estimates where appropriate and investigating the theoretical structure of the assessment with confirmatory factor analysis.

\section{The Bar-On Emotional Quotient Inventory}

Both the EQ-i and its revised version (EQ-i 2.0) can be considered trait or mixed models of EI (O'Boyle et al., 2010; Petrides, Pita \& Kokkinaki, 2007). Bar-On (1997) considered EI to consist of non-cognitive capabilities and skills that have an influence on an individual's ability to cope with environmental demands and pressures. He identified and operationally defined 15 constructs, which formed the model of the EQ-i. They include: Self-regard, Emotional Self-awareness, Emotional Expression, Assertiveness, Independence, Self-actualisation, Empathy, Social Responsibility, Interpersonal Relationship, Reality Testing, Flexibility, Problem Solving, Stress Tolerance, Impulse Control and Optimism. These subscales are further arranged into five composite scales: Intrapersonal, Interpersonal, Adaptability, Stress Management and General Mood.

The EQ-i has recently been revised and the new version, the EQ-i 2.0, was released in 2011 by Multi Health Systems (MHS). According to the manual, the aim with the EQ-i 2.0 was to revise the original model whilst preserving its foundation and integrity (MHS, 2011). A number of revisions were made to the items, scales and overall model. At item level, some were revised whilst new items were also written. This was done to address possible social and cultural bias, to remove items with clinical associations and to improve items that may have been too long or that contained undesirable content. At scale level, the primary concern was to reduce the multidimensional content of a few scales, in particular Emotional Self-awareness, Impulse Control and Self-regard. Problem Solving and Happiness underwent significant changes to improve their interpretability. One new subscale was created called Emotional Expression. In addition, the overall framework of the EQ-i was reconceptualised and resulted in three newly operationalised composite scales. The Intrapersonal, Adaptability and General Mood composite scales on the EQ-i made way for Self-perception, Self-expression, and Decision-making on the EQ-i 2.0. Whilst substantial changes have been made in the EQ-i 2.0, much, if not most, of the original assessment is still reflected in the new version. Thus, previous literature regarding the reliability and factor structure of the EQ-i is still relevant to the present study and is reviewed here.

\section{Reliability}

The reliability of the EQ-i has been well established. Previous research reported Cronbach's alpha internal consistency coefficients ranging between 0.75 and 0.84 (Bar-On, 1997). Similarly, in South Africa, Cronbach's alpha coefficients for the EQ-i ranged between 0.69 and 0.86 , with test reliability of 0.85 after one month dropping to 0.75 after four months (Gallant, 2005). For the EQ-i 2.0, alpha reliabilities range from a low of 0.77 to a high of 0.91 at subscale level, with testretest reliability of 0.92 after two to four weeks, dropping to 0.81 after eight weeks (MHS, 2011). In South Africa, on the recently standardised EQ i 2.0, alpha coefficients ranged between 0.71 and 0.85 at subscale level and 0.84 and 0.88 at composite level (MHS, 2012). Thus, previous research provides ample support for the overall reliability of both the EQ-i and EQ-i 2.0, in South Africa and abroad.

Gignac (2009) has, however, criticised the use of Cronbach's alpha coefficients as estimates of internal consistency reliability. This is because the correct use of this statistic is based on three assumptions that are rarely accounted for in the literature and evidence seems to suggest that they are seldom satisfied in practice (Gignac, Bates \& Lang, 2007). The first assumption requires that the error variance and truescore variance of items do not correlate. This assumption can be considered satisfied if the remaining two assumptions are also satisfied. The second assumption is the condition of tau-equivalence, which requires that each item contributes an equal proportion of variance to the total true-score variance. The third assumption requires that the error terms of the items be uncorrelated. Should the tau-equivalence assumption not be satisfied, Cronbach's alpha will likely be a lower-bound estimate of true reliability. If the uncorrelated error assumption remains unsatisfied, Cronbach's alpha will likely be an overestimate of internal consistency reliability. Accordingly, Gignac recommends McDonald's omega as a more appropriate alternative for the estimation of internal consistency reliability.

In addition, reliability estimates such as Cronbach's alpha are typically computed based on Pearson correlation coefficients, which underestimate the relationship between ordinal variables (Gadermann, Guhn \& Zumbo, 2012). Thus, for ordinal data, such as the Likert-type responses on the EQ-i 2.0, polychoric correlations provide more precise estimates of the true relationship between variables (Carroll, 1961) and subsequently more accurate reliability estimates (Gadermann et al., 2012). The present study will evaluate the internal consistency reliability of the EQ-i 2.0 scales whilst explicitly accounting for the abovementioned criticisms.

\section{Factorial validity}

The factorial validity of the EQ-i was first explored with a principal components analysis (Bar-On, 1997; 2000). Using eigenvalues greater than 1 and scree plots as criteria, BarOn reported a 13-factor solution as the best interpretation of the data. The emergence of 13 factors rather than the expected 15 factors were ascribed to Impulse Control items loading on two factors, Self-regard, Optimism, Happiness and Self-actualisation loading on two factors instead of four and Independence and Assertiveness also loading 
on a single factor. Bar-On conducted confirmatory factor analysis to test whether the subscales loading together had better fit as combined or separable factors. Results suggested that Self-regard, Optimism, Happiness and Self-actualisation could be separated. The same was found for Independence and Assertiveness.

However, Palmer, Manocha, Gignac and Stough (2003) argue that there were a number of problems in Bar-On's (1997) analysis. For example, he did not report the number of eigenvalues greater than 1 or the number of factors suggested by the scree plot. Instead he reported the amount of variance explained by each of the 13 factors although eight of these factors explained less than $2.25 \%$ of the variance, which in large samples is considered to reveal nothing meaningful (Cattell, 1978; Kline, 1994). He also made use of an orthogonal rotation, which was criticised as being inconsistent with the theoretical model. They further argue that many of the constructs are similar at a conceptual level, highly correlated with one another and that the rotation does not allow for the emergence of a general factor. Using principal-axis factoring along with parallel analysis and a scree test as criteria, their results revealed a general factor and six primary factors as best representing the data (Palmer et al., 2003).

Following Bar-On's (1997) model, Petrides and Furnham (2001) made use of confirmatory factor analysis to test the 1-5-15 theoretical model (model 1) but also tested an alternative model with 15 subscales and only one higher order factor (model 2). The composite levels were excluded in the alternative model based on the high correlations amongst them (Dawda \& Hart, 2000). Seeing as both models had reasonable fit, Petrides and Furnham (2001) argue that the second order factors are redundant, but do acknowledge that they might be useful for practitioners.

The factor structure of the EQ-i has also been investigated using exploratory and confirmatory factor analysis in South Africa (Gallant, 2005). Using principal components analysis, a four-factor solution was reported, explaining $28.67 \%$ of the variance. In contrast to expectations, many of the subscales loaded together. Similar to Bar-On's (1997) study, confirmatory factor analysis was used to determine whether the subscales loading together could be treated separately. In each case, models with separated subscales had superior fit and offered significant statistical improvement over models in which the subscales were combined into unidimensional factors (Gallant, 2005).

When the revised version, the EQ-i 2.0, was released in North America, evidence for its factorial validity was published in the new manual (MHS, 2011). In contrast to previous studies, exploratory factor analysis (EFA) was done in line with the theoretical specifications of the revised model. Accordingly, five separate EFAs were conducted. As each composite scale is made up of three subscales, three target factors were specified for extraction, using principal-axis factoring with a direct oblimin rotation.
This could be viewed as an intermediate type of analysis between exploratory and confirmatory factor analysis (Terracciano, 2003). This is because the analysis is clearly guided by the theoretical model when using a target rotation, yet the expected zero and non-zero factor loadings are not specified a priori as in the case with confirmatory factor analysis (Kline, 2011). With the exception of one item, all items loaded significantly on their expected factors with no cross-loadings. This was interpreted as evidence for 15 interpretable factors in line with the theoretical framework of the EQ-i 2.0 (MHS, 2011). It was followed by six confirmatory factor analyses, which included the five composite models tested with EFAs, and an overall model comprising the five composite scales loading on one general factor.

A similar EFA approach has been followed with South African data on the EQ-i 2.0, which yielded similar results to the North American study (MHS, 2012). Although these target rotated EFA results were encouraging, the structure of EQ-i 2.0 has not been investigated using confirmatory factor analysis in this context.

The purpose of this study was to investigate the psychometric properties of the EQ-i 2.0 in South Africa. This was achieved by structuring the research outcomes according to the following objectives:

Objective 1: To investigate item functioning on each subscale of the EQ-i 2.0 from an item response theory perspective using the Rasch model. Fit to the model will be examined for items on each of the 15 subscales of the assessment. No published studies have examined the item functioning of the EQ-i 2.0 in South Africa from an IRT perspective.

Objective 2: Although the reliability of the EQ-i and the EQ-i 2.0 appear to be satisfactory, the use of Cronbach's alpha has been criticised as an estimate of internal consistency reliability in EI research (Gignac, 2009). This study will explicitly test the assumptions of Cronbach's alpha using confirmatory factor analysis. Specifically, it will be used to test the assumptions of tau-equivalence and uncorrelated error terms. For tau-equivalence, goodness of fit will be evaluated for models in which the factor loadings have been constrained to equality. Next, the uncorrelated error assumption will be tested by relaxing the constraint of equal factor loadings and then examining the degree to which the items of each subscale conform to a well-fitting confirmatory factor analytic model. Cronbach's alpha reliability estimates will be computed for subscales that satisfy these assumptions and McDonald's omega estimates will be computed for subscales that violate the assumptions. This process will also allow for considerations of construct validity at subscale level. As far as the author is aware, no studies have examined the internal consistency reliability of the EQ-i 2.0 following this approach. 
Objective 3: In addition to the confirmatory factor analytic models tested at subscale level to evaluate Cronbach's assumptions, a further six confirmatory factor models will be tested. In line with the theoretical model, five composite models will be specified, each comprising three factors loading on a composite factor. Lastly, an overall model will be tested in which five composite scales load onto an overall EI factor.

The review of the literature revealed a need for a comprehensive psychometric examination of the EQ-i 2.0 in South Africa. Although the assessment is used extensively elsewhere in the world, it is necessary to ensure that it functions appropriately in this context. In addition, a number of criticisms have been levied against the estimation of reliability in the EI literature in particular. This study seeks to address these gaps in the literature.

\section{Research design \\ Research approach}

The present study falls within the quantitative research paradigm. A cross-sectional survey design was used comprising secondary data. The analytic methods employed were correlational in nature.

\section{Research method Research participants}

The sample consisted of 1144 working adults, comprising 570 men and 574 women. The data were collected for the purpose of standardising the assessment in South Africa and was completed online. The ethnic representation included 414 black, 341 white, 87 mixed-race and 96 Indian or Asian participants; 206 individuals did not endorse any of the specified categories. Around $25 \%$ of the sample was represented in each of the following four age categories: 18 29 years, 30-39 years, $40-49$ years and 50 years and older.

\section{Measuring instruments}

The EQ-i 2.0 is a self-report assessment comprising 133 items to which participants have to indicate the degree to which each statement reflects the way they usually think or feel on a five-point Likert scale. Item responses are summed to scale, composite and overall emotional intelligence scores, which are all converted to standardised scores. An inconsistency index comprising 10 item pairs indicates possible random responding. Six items are also used to detect whether participants are trying to create an exaggerated positive (PI) or negative impression (NI). The last item asks whether the participants were open and honest when responding.

\section{Statistical analysis}

Rasch analysis works on the assumption that an individual has an increased probability of scoring higher on a test if the individual possesses more of the latent construct being measured (Green \& Frantom, 2002). Accordingly, the probability of a particular response on an item is a function of the item difficulty (endorsability) and the person's ability (standing on the latent trait). Since the Rasch model requires that data fit the model (Bond \& Fox, 2007), item fit will be examined for each of the EQ-i 2.0 subscales. Misfitting items do not function in accordance with the model's requirements. Overfit means that the item is too predictable and may not be contributing any unique information whereas underfit indicates low predictability and that the item may be measuring something unexpected (Bond \& Fox, 2007). Infit mean square values of less than 0.60 and greater than 1.40 were considered acceptable and in line with the recommendation by Bond and Fox (2007) for Likerttype items.

A number of confirmatory factor analytic models were evaluated in this study. Firstly, for each subscale, the tau-equivalence and uncorrelated error assumptions of Cronbach's alpha were examined. Thus, two models were specified for each subscale. These results were used to determine whether Cronbach's alpha or McDonald's omega estimates of internal consistency would be most appropriate to compute. It also indicated the extent to which a single unidimensional scale accounted for the observed scores on each subscale. Following this, five models were specified, each representing a composite scale of the EQ-i 2.0. Lastly, an overall model with five factors loading on a general EI factor was specified.

McDonald's (1970) omega $(\omega)$ is a latent variable approach to estimate internal consistency reliability (Gignac, 2009). Two omegas in particular are relevant to this discussion: omega-A $(\omega \mathrm{A})$ and omega $B(\omega \mathrm{B})$. The former should be used in those cases where there are no correlations between the error terms and where the factor loadings may not be equal across items (not tau-equivalent). It should be noted at this point that the impact of non-equivalent factor loadings is usually not very substantial (Reuterberg \& Gustafsson, 1992). The formula for $\omega \mathrm{A}$ can be represented as follows:

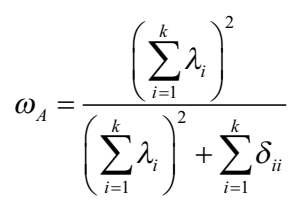

In this equation, $\lambda_{\mathrm{i}}$ is the standardised factor loading and $\delta \mathrm{ii}$ is the standardised error variance (i.e. $1-\lambda_{i}^{2}$ ). For data where the error terms are correlated, the second omega $(\omega \mathrm{B})$ should be used. It can be formulated as follows:

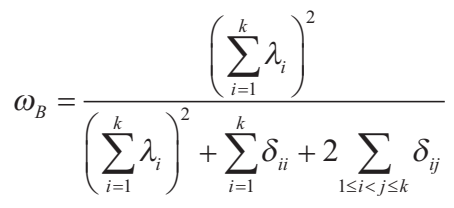

In this equation, $\lambda i$ and $\delta i$ are defined as above and $\delta i j$ is equal to the correlations between item error terms. McDonald's omega can therefore be used to accurately estimate internal consistency reliability with data that do not conform to the assumptions of Cronbach's alpha. Gignac (2009) argues that researchers in the area of EI do not often, if ever, test 
these assumptions and considers it likely that estimates of reliability will be inaccurate. In the present study, the assumptions of tau-equivalence and uncorrelated errors were explicitly tested using confirmatory factor analysis as described above.

\section{Results \\ Item response theory analysis}

The results displayed in Table 1 show that the infit mean square mean values for the subscales were all close to the expected value of 1 , demonstrating acceptable fit overall. At subscale level, there was one item on the Stress Tolerance scale that overfit the model. This suggests that this item might not be contributing anything worthwhile to the construct being measured. One item each on the Emotional Expression, Empathy and Optimism scales underfit the model, indicating that these items may be measuring something unexpected. Thus, a total of four items on the EQ-i 2.0 were identified as misfitting the Rasch model. Overall, the results indicated good fit for almost all the items of the assessment on their respective subscales.

\section{Confirmatory factor analysis}

The confirmatory factor analysis was computed on the R-statistics freeware platform, version 2.15.1, using the lavaan package (Rosseel, 2012). Given the five-point Likert response scale of the EQ-i 2.0, Weighted Least Squares Mean and Variance (Muthén, Du Toit, \& Spisic, 1997) corrected estimation was used. This method has shown to be superior to maximum likelihood (ML) estimation with up to five response categories (Beauducel \& Herzberg, 2006). This estimator creates a polychoric correlation matrix, which is also more appropriate than Pearson correlations for calculating reliability with ordinal data (Gadermann et al., 2012). Although a few outliers were detected on a number of subscales, there was no strong theoretical motivation to disregard these cases. For example, there is no reason to consider a very low score on Self-regard as too low to be a valid response. The total sample of 1144 contained no missing data.
In order to test the assumption of tau-equivalence, confirmatory factor analysis was conducted on each of the EQ-i 2.0 subscales, with factor loadings constrained to be equal. Inspection of the tau-equivalent fit values in Table 2 shows that Problem Solving demonstrated acceptable fit when testing for this assumption. It could be argued that Selfactualisation, Emotional Self-awareness, Independence and Reality Testing also approximated well-fitting tau-equivalent models, despite some fit indicators falling just short of the ideal cut-off values (MacCallum, Browne \& Sugawara, 1996; Schreiber, Nora, Stage, Barlow \& King, 2006).

\section{Internal consistency reliability}

Seeing that only the Problem Solving, Self-actualisation, Emotional Self-awareness, Independence and Reality Testing scales largely conformed to the assumptions upon which Cronbach's alpha reliability is based, calculating this coefficient for the remaining scales on the EQ-i 2.0 would be inappropriate. Instead, more suitable McDonald's omega estimates were computed and are reported in Table 3. Omega estimates were also computed for the tau-equivalent scales and, as expected, were equal to the Cronbach's alpha coefficients.

Five CFA models were specified next, each according to the theoretical composite structure of the EQ-i 2.0. Thus, for each model, three factors were specified to load onto one higher order factor. Fit indices for each of the models are reported in Table 4. Inspection of the absolute fit indicators for the congeneric models suggests that the models fit the data reasonably well. The incremental fit values were less promising, particularly for the Self-expression, Interpersonal and Stress Tolerance scales. Modification indices were considered and a few parameters were re-specified on each model. The fit values for the re-specified models are also displayed in Table 4. The modified models fit the data moderately well with the exception of the comparative fit index and Tucker-Lewis index values on the Self-expression and Interpersonal composite scales, which fell outside the ideal range for these indicators. Fit for the total EQ model was not satisfactory. Modification indices were not considered

TABLE 1: Number of items that misfit the Rasch model.

\begin{tabular}{lllll}
\hline Item & IMNSQ mean & IMNSQ standard deviation & Number of underfit items & Number of overfit items \\
\hline Self-regard & 1.01 & 0.26 & 0 & 0 \\
Self-actualisation & 1.05 & 0.15 & 0 & 0 \\
Emotional Self-awareness & 1.01 & 0.19 & 1 & 0 \\
Emotional Expression & 1.04 & 0.28 & 0 & 0 \\
Assertiveness & 1.00 & 0.19 & 0 & 0 \\
Independence & 1.03 & 0.15 & 0 & 0 \\
Interpersonal Relationships & 1.01 & 0.19 & 1 & 0 \\
Empathy & 1.00 & 0.26 & 0 & 0 \\
Social Responsibility & 1.00 & 0.12 & 0 & \\
Problem Solving & 1.03 & 0.17 & 0 & 0 \\
Reality Testing & 1.02 & 0.15 & 0 & 0 \\
Impulse Control & 1.00 & 0.23 & 0 \\
Flexibility & 0.99 & 0.12 & 0 \\
Stress Tolerance & 1.01 & 0.21 & 0 \\
Optimism & 1.02 & 0.21 & 0 \\
\hline
\end{tabular}

IMNSQ, Infit mean square. 
TABLE 2: Fit statistics for the Emotional Quotient Inventory 2.0 subscales.

\begin{tabular}{|c|c|c|c|c|c|c|c|c|c|}
\hline \multirow[t]{2}{*}{ Scale } & \multicolumn{3}{|c|}{ Tau-equivalence } & \multicolumn{3}{|c|}{ Congeneric model } & \multicolumn{3}{|c|}{ Model with modifications } \\
\hline & CFI & TLI & RMSEA & CFI & TLI & RMSEA & CFI & TLI & RMSEA \\
\hline Self-regard & 0.946 & 0.944 & 0.107 & 0.975 & 0.966 & 0.083 & - & - & - \\
\hline Self-actualisation & 0.972 & 0.971 & 0.067 & 0.981 & 0.975 & 0.062 & - & - & - \\
\hline Emotional Self-awareness & 0.955 & 0.953 & 0.087 & 0.987 & 0.980 & 0.057 & - & - & - \\
\hline Emotional Expression & 0.935 & 0.933 & 0.129 & 0.972 & 0.960 & 0.100 & 0.990 & 0.982 & 0.067 \\
\hline Assertiveness & 0.911 & 0.906 & 0.099 & 0.991 & 0.987 & 0.037 & - & - & - \\
\hline Interpersonal & 0.913 & 0.910 & 0.122 & 0.972 & 0.961 & 0.080 & - & - & - \\
\hline Empathy & 0.899 & 0.896 & 0.155 & 0.951 & 0.935 & 0.123 & 0.990 & 0.983 & 0.062 \\
\hline Social Responsibility & 0.906 & 0.899 & 0.122 & 0.981 & 0.968 & 0.068 & - & - & - \\
\hline Problem Solving & 0.982 & 0.982 & 0.057 & 0.987 & 0.981 & 0.058 & - & - & - \\
\hline Reality Testing & 0.948 & 0.946 & 0.085 & 0.988 & 0.984 & 0.047 & - & - & - \\
\hline Impulse Control & 0.836 & 0.829 & 0.149 & 0.987 & 0.982 & 0.048 & - & - & - \\
\hline Stress Tolerance & 0.929 & 0.926 & 0.138 & 0.979 & 0.970 & 0.087 & - & - & - \\
\hline Optimism & 0.853 & 0.847 & 0.192 & 0.980 & 0.972 & 0.082 & - & - & - \\
\hline
\end{tabular}

CFI, Comparative fit index; RMSEA, root mean square error of approximation; TLI, Tucker-Lewis index.

TABLE 3: Internal consistency reliability estimates for the Emotional Quotient Inventory 2.0 scales.

\begin{tabular}{ll}
\hline Scale & Reliability \\
\hline Total EQ & $0.96(\alpha=\omega)$ \\
Self-perception Composite & $0.91(\omega \mathrm{B})$ \\
Self-expression Composite & $0.89(\omega \mathrm{B})$ \\
Interpersonal Composite & $0.91(\omega \mathrm{B})$ \\
Decision-making Composite & $0.91(\omega \mathrm{B})$ \\
Stress Management Composite & $0.91(\omega \mathrm{B})$ \\
Self-regard & $0.90(\omega \mathrm{A})$ \\
Self-actualisation & $0.88(\alpha=\omega)$ \\
Emotional Self-awareness & $0.82(\alpha=\omega)$ \\
Emotional Expression & $0.83(\omega \mathrm{B})$ \\
Assertiveness & $0.79(\omega \mathrm{A})$ \\
Independence & $0.80(\alpha=\omega)$ \\
Interpersonal Relationships & $0.81(\omega \mathrm{B})$ \\
Empathy & $0.82(\omega \mathrm{B})$ \\
Social Responsibility & $0.79(\omega \mathrm{A})$ \\
Problem Solving & $0.88(\alpha=\omega)$ \\
Reality Testing & $0.83(\alpha=\omega)$ \\
Impulse Control & $0.81(\omega \mathrm{A})$ \\
Flexibility & $0.72(\omega \mathrm{B})$ \\
Stress Tolerance & $0.89(\omega \mathrm{A})$ \\
Optimism & $0.88(\omega \mathrm{A})$ \\
Happiness & $0.86(\omega \mathrm{B})$ \\
\hline E &
\end{tabular}

$E Q$, emotional quotient; $\alpha$, alpha; $\omega A$, omega-A; $\omega B$, omega-B.

for this model as it would have resembled a witch-hunt to improve fit that is unlikely to be theoretically meaningful.

\section{Discussion}

The purpose of this study was to examine the psychometric properties of the EQ-i 2.0 in South Africa. Item functioning was investigated using the Rasch model and the average infit mean square estimates were close to the expected value of 1 for all the subscales. A total of four items were identified that misfit the model. The Emotional Expression, Empathy, and Optimism scales each had one underfitting item, which suggests that these items may be measuring something slightly different relative to the other items on the respective scales. Stress Tolerance had one overfitting item, showing that the item may not be contributing any unique information to the construct being measured.

To address Gignac's (2009) reliability related criticisms, each of the EQ-i 2.0 subscales was subjected to confirmatory factor analysis to test whether it satisfied the assumptions for computing Cronbach's alpha. Only five scales largely conformed to the assumption of tau-equivalence. Eight scales satisfied the assumption of uncorrelated error terms and three scales violated both assumptions. Thus, with the exception of Self-actualisation, Emotional Self-awareness, Independence, Problem Solving and Reality Testing, which were tau-equivalent, computing Cronbach's reliability coefficients for the remaining subscales was inappropriate. Omega-A reliability estimates (for scales violating the assumption of tau-equivalence) were computed for Selfregard, Assertiveness, Interpersonal, Social Responsibility, Impulse Control, Stress Tolerance and Optimism. Omega-B reliabilities (for scales violating the assumption of uncorrelated error terms) were calculated for Emotional Expression, Empathy and Flexibility. With the exception of Flexibility, the all subscale reliabilities ranged between a low of 0.79 to a high of 0.90 , which was satisfactory.

Omega B reliability estimates were also computed for the five composite scales, as a number of correlated error terms were identified on each. The composite reliabilities were nevertheless good, ranging between 0.89 and 0.91 . Overall, the internal consistency reliabilities estimated in this study are in line with other research that reported satisfactory results for the scales of the EQ-i and EQ-i 2.0 (Bar-On, 1997; Gallant, 2005; MHS, 2011, 2012). It is noteworthy that the present reliability results seem to be better than those reported previously for the EQ-i 2.0 in South Africa (MHS, 2012). This can likely be attributed to the use of polychoric rather than Pearson correlations, which better account for the true relationship between variables when working with ordinal data (Gadermann et al., 2012). Also, Cronbach's alpha tends to be a lower-bound estimate of reliability 
TABLE 4: Fit statistics for the composite scales of the Emotional Quotient Inventory 2.0.

\begin{tabular}{|c|c|c|c|c|c|c|c|c|}
\hline \multirow[t]{2}{*}{ Composite scale } & \multicolumn{4}{|c|}{ Congeneric models } & \multicolumn{4}{|c|}{ Modified models } \\
\hline & CFI & TLI & RMSEA & SRMR & CFI & TLI & RMSEA & SRMR \\
\hline Self-perception & 0.931 & 0.924 & 0.043 & 0.038 & 0.946 & 0.939 & 0.038 & 0.035 \\
\hline Self-expression & 0.874 & 0.860 & 0.057 & 0.063 & 0.920 & 0.906 & 0.046 & 0.055 \\
\hline Interpersonal & 0.870 & 0.855 & 0.065 & 0.064 & 0.925 & 0.911 & 0.051 & 0.052 \\
\hline Decision-making & 0.936 & 0.929 & 0.038 & 0.041 & 0.952 & 0.945 & 0.034 & 0.038 \\
\hline Stress Management & 0.894 & 0.883 & 0.056 & 0.049 & 0.945 & 0.937 & 0.041 & 0.041 \\
\hline Total EQ & 0.746 & 0.686 & 0.150 & 0.091 & - & - & - & - \\
\hline
\end{tabular}

CFI, Comparative fit index; RMSEA, root mean square error of approximation; SRMR, root mean square residual; TLI, Tucker-Lewis index; EQ, emotional quotient.

when it violates the tau-equivalence assumption, which most subscales did. However, for the Emotional Expression, Empathy and Flexibility scales that violated the assumption of uncorrelated error terms, Cronbach's alpha would have overestimated reliability.

The results also provided good support for the construct validity of the subscales of the EQ-i2.0. This was demonstrated by the fact that five scales yielded good fit with their factor loadings constrained to equality, eight yielded good fit with their factor loadings unconstrained and only three scales required the use of modification indices to produce adequate fit. As the assessment is designed to also report and interpret the subscale scores, the results support construct validity for the use of the assessment at this level. This is in line with previous research showing that the subscales can be treated as separable factors (Bar-On, 1997; Gallant, 2005; MHS, 2011; Petrides \& Furnham, 2001).

At the composite level, the congeneric models yielded reasonable fit when inspecting the absolute fit indices, although the incremental fit indices were weaker, especially on the Self-expression, Interpersonal and Stress Management scales. Re-specifying the models, by allowing a number of error terms to covary on each model, resulted in reasonable fit on all five models. These results seem to support the composite factor structure of the EQ-i 2.0 as specified by the theoretical model and are in line with the findings reported by the test publisher (MHS, 2011).

Fit on the total EQ model was not satisfactory on any of the fit indices. The reason for the weak fit on this model could possibly be ascribed to the size of the model given the number of variables included (Kenny \& McCoach, 2003). However, it is also possible that there might be dimensionality problems when considering the overall model, which remain obscured when considering the composite scales separately. Palmer et al. (2003) criticised Bar-On's (1997) original research on the EQ-i and reported an alternative and more parsimonious factor structure in their research. Indeed, it is a valid criticism since very little of the reported literature deliberately investigated alternative factor structures for the assessment although it is well known to researchers that a well-fitting confirmatory model does not preclude the existence of good alternative models (Kline, 2011). Thus, it is possible that the dimensional structure of the EQ-i 2.0 might look substantially different when examined using exploratory factor analysis without the use of target rotations in line with the theoretical model.

\section{Limitations and recommendations}

It is therefore a limitation of this study that the factor structure of the EQ-i 2.0 was examined only with confirmatory factor analysis in line with the theoretical model. This prevented consideration of alternative models that may account for the data equally well or better. As mentioned above, this may also obscure dimensionality problems between the composite scales. However, investigating the factor structure, as specified by the theoretical model, is an important departure point since it is the way the assessment is scored and interpreted in practice. It is recommended that future research focus on the dimensional structure of the EQ-i 2.0, with the particular aim of identifying overlapping constructs and experimenting with alternative and more parsimonious models. It is further recommended that future studies investigate the measurement invariance of the EQ-i 2.0, as it represents another important aspect of psychometric functioning relevant to South Africa.

\section{Conclusion}

In summary, the results of this study are in line with previous research, which has reported acceptable psychometric properties for the EQ-i and the modified EQ-i 2.0. In particular, this study has demonstrated that almost all the items on the EQ-i 2.0 subscales function as expected using Rasch analysis. Internal consistency reliability was explored in great detail and yielded satisfactory results. The confirmatory factor analytic results supported previous findings with exploratory factor analysis in South Africa. Overall, with the exception of the total EQ model, the results of this study seem to support the reliability and factorial validity of the EQ-i 2.0 in the South African context.

\section{Acknowledgements Competing interests}

This research was conducted whilst the author (Casper J.J. van Zyl) was employed by JvR Psychometrics, who distributes the EQ-i 2.0 in South Africa.

\section{References}

Bar-On, R. (1997). Emotional Quotient Inventory: Technical manual. Toronto, Canada: Multi-Health Systems.

Bar-On, R. (2000). Emotional and social intelligence: Insights from the Emotional Quotient Inventory. In R. Bar-On, \& J. D. A. Parker (Eds.), The handbook of emotional intelligence (pp. 363-388). San Francisco, CA: Jossey-Bass.

Beauducel, A., \& Herzberg, P.Y. (2006). On the performance of maximum likelihood versus means and variance adjusted weighted least squares estimation in CFA. dx.doi.org/10.1207/s15328007sem1302_2 
Bond, T.G., \& Fox, C.M. (2007). Applying the Rasch model. Mahwah, NJ: Lawrence Erlbaum Associates.

Cameron, A. (1999). WPQei users guide. London, UK: The Test Agency Limited.

Carroll, J.B. (1961). The nature of data, or how to choose a correlation coefficient. Psychometrika, 26, 347-372. http://dx.doi.org/10.1007/BF02289768

Cattell, R.B. (1978). The scientific use of factor analysis. New York, NY: Plenum. http:// dx.doi.org/10.1007/978-1-4684-2262-7

Conte, J.M. (2005). A review and critique of emotional intelligence measures. Journa of Organizational Behavior, 26, 433-440. http://dx.doi.org/10.1002/job.319

Cooper, R.K., \& Sawaf, A. (1997). Executive EQ: Emotional intelligence in leadership and organizations. New York. NY: Grosset/Putnum.

Daus, C.S., \& Ashkanasy, N.M. (2005). The case for the ability-based model of emotional intelligence in organizational behavior. Journal of Organizationa Behavior, 26, 453-466. http://dx.doi.org/10.1002/job.321

Dawda, D., \& Hart, S.D. (2000). Assessing emotional intelligence: Reliability and validity of the Bar-On Emotional Quotient Inventory (EQ-i) in university students. Personality and Individual Differences, 28, 797-812. http://dx.doi.org/10.1016/ S0191-8869(99)00139-7

Gadermann, A.M., Guhn, M., \& Zumbo, B.D. (2012). Estimating ordinal reliability for Likert-type and ordinal items response data: A conceptual, empirical and practical guide. Practical Assessment, Research and Evaluation, 17(3), 1-13.

Gallant, M.A. (2005). EQ-i South African norms. MHS technical report No 0035 Toronto, Canada: Multi-Health Systems.

Gignac, G.E. (2009). Psychometrics and the measurement of emotional intelligence. In C. Stough, D.H. Saklofske, J.D.A. Parker (Eds.), Assessing emotional intelligence: Theory, research and application (pp. 9-40). New York, NY: Springer. http://dx.doi. Theory, research and application (pp.
org/10.1007/978-0-387-88370-0_2

Gignac, G.E., Bates, T.C., \& Lang, K.L. (2007). Implications relevant to CFA model misfit, reliability and the five-factor model as measured by the NEO-FFI. Personality and Individual Differences, 43, 1051-1062. http://dx.doi.org/10.1016/j. paid.2007.02.024

Goleman, D. (1995). Emotional intelligence: Why it can matter more than IQ. New York, NY: Bantam Books.

Green, K.E., \& Frantom, C.G. (2002). Survey development and validation with the Rasch model. Paper presented at the International Conference on Questionnaire development, Evaluation, and Testing, Charlesston, SC, 14-17 November.

Jordan, P.J., Ashkanasy, N.M., Hartel, C.E.J., \& Hooper, G.S. (2002). Workgroup emotional intelligence: Scale development and relationship to team process effectiveness and goal focus. Human Resource Management Review, 12, 195-214. http://dx.doi.org/10.1016/S1053-4822(02)00046-3

Joseph, D.L., \& Newman, D.A. (2010). Emotional intelligence: An integrative metaanalysis and cascading model. Journal of Applied Psychology, 95, 54-78. http:// dx.doi.org/10.1037/a0017286

Kenny, D.A., \& McCoach, D.B. (2003). Effect of the number of variables on measures of fit in structural equation modeling. Structural Equation Modeling, 10, 333-351. $\mathrm{http}: / /$ dx.doi.org/10.1207/S15328007SEM1003_1

Kline, P. (1994). An easy guide to factor analysis. London, UK: Routledge.

Kline, R.B. (2011). Principles and Practice of Structural Equation Modelling. New York: The Guilford Press.

Locke, E. A. (2005). Why emotional intelligence is an invalid concept. Journal of Organizational Behavior, 26(4), 425-431. http://dx.doi.org/10.1002/job.318

MacCallum, R.C., Browne, M.W., \& Sugawara, H.M. (1996). Power analysis and determination of sample size for covariance structure modeling. Psychological Methods, 1, 130-149. http://dx.doi.org/10.1037/1082-989X.1.2.130
Matthews, G., Zeidner, M., \& Roberts, R.D. (2002). Emotional intelligence: Science and myth. Cambridge, MA: MIT Press.

Mayer, J.D., Salovey, P., Caruso, D., \& Sitarenios, G. (2003). Measuring emotional intelligence with the MSCEIT V2.0. Emotion, 3, 97-105.

McDonald, R.P. (1970). The theoretical foundations of principal factor analysis, canonical factor analysis, and alpha factor analysis. British Journal of Statistical and Mathematical Psychology, 23, 1-21. http://dx.doi.org/10.1111/j.2044-8317.1970. tb00432.x

Multi Health Systems (2011). Emotional Quotient Inventory 2.0: Users handbook. Retrieved November 07, 2013, from http://ei.mhs.com/eq20_manual/part5/ EqiStages.html

Multi Health Systems (2012). Emotional Quotient Inventory 2.0: Users handbook. Retrieved November 07, 2013, from http://ei.mhs.com/eq20_manual/part5/ ProfessionalNorms4.html

Muthén, B., Du Toit, S.H.C. \& Spisic, D. (1997). Robust inference using weighted least squares and quadratic estimating equations in latent variable modeling with categorical and continuous outcomes. Accepted for publication in Psychometrika.

O'Boyle, E.H. Jr, Humphrey, R.H., Pollack, J.M., Hawver, T.H., \& Story, P.H. (2010). The relation between emotional intelligence and job performance: A meta-analysis. Journal of Organizational Behavior, 32, 788-818. http://dx.doi.org/10.1002/ job.714

Palmer, B.R., Monocha, R., Gignac, G., \& Stough, C. (2003). Examining the factor structure of the Bar-On Emotional Quotient Inventory with an Australian general population sample. Personality and Individual Differences, 35, 1191-1210. http:// dx.doi.org/10.1016/S0191-8869(02)00328-8

Petrides, K. V., \& Furnham, A. (2001). Trait emotional intelligence: Psychometric investigation with reference to established trait taxonomies. European Journal of Personality, 15, 425-448. http://dx.doi.org/10.1002/per.416

Petrides, K.V., Pita, R. \& Kokkinaki, F. (2007). The location of trait emotional intelligence in personality factor space. British Journal of Psychology, 98, 273-289. http://dx.doi.org/10.1348/000712606X120618

Reuterberg, S.E., \& Gustafsson, J.E. (1992). Confirmatory factor analysis and reliability: Testing measurement model assumptions. Educational and Psychological Measurement, 52, 795-811. http://dx.doi.org/10.1177/0013164492052004001

Rosseel, Y. (2012). lavaan: An R package for structural equation modeling. Journal of Statistical Software, 48(2), 1-36.

Salovey, P., \& Mayer, J.D. (1990). Emotional intelligence. Imagination, Cognition and Personality, 9, 185-211. http://dx.doi.org/10.2190/DUGG-P24E-52WK-6CDG

Schreiber, J.B., Nora, A., Stage, F.K., Barlow, E.A., \& King, J. (2006). Reporting structural equation modelling and confirmatory factor analysis results: A review. Journal of Educational Research, 99(6), 323-327. http://dx.doi.org/10.3200/JOER.99.6.323338

Schutte, N.S., Malouff, J.M., Hall, L.E., Haggerty, D.J., Cooper, J.T., \& Golden, C.J. (1998). Development and validation of a measure of emotional intelligence. Personality and Individual Differences, 25, 167-177. http://dx.doi.org/10.1016/ S0191-8869(98)00001-4

Terracciano, A. (2003). The Italian version of the NEO-PI-R: Conceptual and empirical support for the use of targeted rotation. Personality and Individual Differences, 35, 1859-1872. http://dx.doi.org/10.1016/S0191-8869(03)00035-7

Van Rooy, D., \& Viswesvaran, C. (2004). Emotional intelligence: A meta-analytic investigation of predictive validity and nomological net. Journal of Vocational Behavior, 65, 71-95. http://dx.doi.org/10.1016/S0001-8791(03)00076-9

Wong, C.S., \& Law, K.S. (2002). The effects of leader and follower emotional intelligence on performance and attitude: An exploratory study. Leadership Quarterly, 13, 243-274. http://dx.doi.org/10.1016/S1048-9843(02)00099-1 